\title{
KERAGAAN ADOPSI TEKNOLOGI INSEMINASI BUATAN (IB) KAMBING DI KECAMATAN ANDOOLO KABUPATEN KONAWE SELATAN
}

\author{
Julian Witjaksono ${ }^{1^{*}}$ \\ ${ }^{1}$ Balai Pengkajian Teknologi Pertanian (BPTP) Sulawesi Tenggara \\ *Corresponding author: julian_witjaksono@yahoo.com
}

To cite this article:

Witjaksono, J. (2020). Keragaan Adopsi Teknologi Inseminasi Buatan (IB) Kambing di Kecamatan Andoolo Kabupaten Konawe Selatan. JIA (Jurnal Ilmiah Agribisnis) : Jurnal Agribisnis dan IImu Sosial Ekonomi Pertanian, 5(4), 123 - 130. doi:http://dx.doi.org/10.37149/jia.v5i4.13096

Received: July 25, 2020; Accepted: August 25, 2020; Published: August 31, 2020

\begin{abstract}
Goat farming system has long been carried out by farmers in Indonesia, is the essential farm for smallholder farmers, especially in rural areas as the cash money for income generation. However, farmers have been facing reproductive inefficiency and low meat productivity. Therefore, Artificial Insemination technology has been implemented for genetic improvement of goats in order to increase the sale value of livestock, increasing livestock productivity, and to accelerate genetic gain in local goat. This study was conducted to find the performance of the implementation of Al technology using Boer frozen semen. This study was carried out in Bina Marwa Village and Mata Up Village Andoolo Sub District, South Konawe District of Southeast Sulawesi Province in 2018. Study findings show that the farmer assessment of implementing Al technological innovation based on these innovations in terms of profits, compatibility, easily implementing, triability, and observability indicated a good percentage $(59.87 \%)$, quite good $(11.87 \%)$ and not good $(28.26 \%)$. In addition, this technology has been deployed across the village and rapidly adopted among the farmers due to the low-cost of introducing Al technology, and the better physical appearance of genetic improvement $(100 \%)$, respectively. Another driving factor was the favorable Al technology $(80 \%)$ and that is easily applied $(60 \%)$.
\end{abstract}

Keywords: adopted; artificial insemination; farming system; livestock; technology

\section{PENDAHULUAN}

Kambing adalah salah satu jenis ternak ruminansia yang cukup populer dikembangkan oleh masyarakat selain sapi khususnya di wilayah pedesaan. Kemudahan beradaptasi di wilayah pegunungan menjadi pilihan masyarakat untuk beternak kambing. Namun, pada umumnya beternak kambing masih menjadi usaha sampingan bagi rumah tangga petani dan belum dikembangkan secara komersial. Pola usaha yang selama ini dikembangkan masih dalam skala usaha yang tradisional dengan rata-rata kepemilikan ternak 2-3 ekor (Susanto \& Dahlan, 2017). Lebih lanjut, bobot badan kambing Kacang dan Peranakan Etawah (Rahmah, Imanudin \& Permadi, 2018)) pada umur satu tahun baru mencapai sekitar $14-17 \mathrm{~kg}$, sedangkan bobot badan pada kambing sub tropis mencapai rata rata $20 \mathrm{~kg}$ pada umur satu tahun (Maesya \& Rusdiana, 2018). Jenis kambing sub tropis di Indonesia memiliki potensi genetik yang baik apabila dipelihara dengan manajemen yang baik maka tingkat produktivitas akan meningkat. Pada umumnya tujuan produksi dari pemeliharaan kambing yang dikembangkan oleh peternak tidak sesuai dengan spesialisasi (Rahmah et al., 2018). Di samping itu upaya untuk melaksanakan pemuliaan ternak kambing oleh petani ternak masih sangat sedikit. Hal ini disebabkan karena rendahnya keterampilan peternak, rendahnya jumlah petugas inseminator, belum adanya program breeding terutama di wilayah pedesaan, dan tidak adanya dukungan perda atau kebijakan Pemda terkait program pemuliaan hewan ternak (Kurniasih, Fuah, \& Pryanto, 2013).

Upaya peningkatan produktivitas ternak dapat dilakukan melalui perbaikan manajemen pemeliharaan diantaranya formulasi ransum ternak dan manajemen kawin ternak, hal ini disebabkan karena metode seleksi ternak memerlukan proses yang panjang dan membutuhkan ongkos produksi 
yang tinggi (Riyadhi, Rizal, \& Wahdi, 2017). Penerapan teknologi Inseminasi Buatan (IB) merupakan alternatif metode kawin ternak dalam upaya peningkatan produktivitas ternak kambing. Hal ini disebabkan karena perkawinan alami membutuhkan pejantan sebagai pemacek (Hasri, Suharyati, \& Sulastri, 2018). Teknologi IB memiliki beberapa manfaat yaitu terpeliharanya sumber penjantan unggul dalam bentuk semen dan menghindari terjadinya inbreeding akibat kawin alami yang dapat mengakibatkan rendahnya mutu genetik ternak (Adhianto et al., 2019). Kecamatan Andoolo merupakan salah satu wilayah yang merupakan pengembangan ternak kambing yang pada umumnya dipelihara secara ekstensif dan sebagian besar merupakan jenis kambing kacang (Masrah, Hafid, \& Saili, 2016).

Upaya meningkatkan produktivitas ternak, di lokasi kajian telah dilaksanakan program IB untuk sapi potong yang telah dicanangkan sejak tahun 2005, namun untuk ternak kambing belum pernah dilaksanakan program kawin suntik. Oleh sebab itu, kegiatan IB di 2 desa di lokasi kajian yaitu di kecamatan Andoolo merupakan program yang baru dilaksanakan sebagai inisiator Inseminasi Buatan pada ternak kambing. Kajian yang dilakukan oleh (Masrah et al., 2016) di Kecamatan Andoolo menunjukan bahwa program inseminasi buatan pada kambing harus dikembangkan sebagai upaya peningkatan perbaikan genetik disamping pola pemeliharaan yang intensif sehingga produktivitas ternak dapat ditingkatkan. Lebih lanjut, kajian adopsi inovasi teknologi terhadap keberhasilan program IB pada hewan ternak khususnya kambing masih banyak yang belum dilakukan (Nugraha, Abdullah, \& Sirajuddin, 2016). Oleh sebab itu, penelitian ini merupakan studi tentang adopsi inovasi teknologi IB pada ternak kambing untuk melihat tingkat adopsi peternak kambing dan keberhasilan program IB pada ternak kambing.

\section{MATERI DAN METODE}

Kegiatan kajian adopsi inovasi teknologi Inseminasi Buatan (IB) pada ternak kambing telah dilaksanakan mulai bulan Oktober 2018 - Desember 2018. Lokasi kajian dilaksanakan di Desa Bina Marwa dan Desa Mata Upe Kecamatan Andoolo Kab. Konawe Selatan. Pemilihan desa sampel berdasarkan pertimbangan bahwa lokasi tersebut merupakan wilayah yang menjadi pengembangan program IB ternak kambing yang dilaksanakan oleh Pemerintah Daerah Kabupaten Konawe Selatan.

Data yang dikumpulkan berdasarkan survey dan hasil wawancara dengan menggunakan kuisioner dengan responden petani kooperator (peternak yang mengikuti program IB) yang berjumlah 15 orang dan non kooperator (peternak yang tidak mengikuti program IB) yang berjumlah 15 orang di dua desa sampel, sehingga seecara keseluruhan jumlah responden adalah 60 orang. Survey dan wawancara di bagi dalam 3 tahapan, yaitu tahap (1) survey dan observasi serta wawancara untuk mengetahui karakteristik sistem usaha ternak kambing dan keragaan ushatani peternak di lokasi kajian, tahap (2) yaitu survey dan wawancara untuk mengetahui sikap dan persepsi peternak terhadap teknologi IB, dan tahap akhir yaitu survey dan wawancara untuk mengetahui tingkat adopsi teknologi IB kambing di lokasi kajian.

Data yang dikumpulkan selanjutnya di tabulasi dan dianalisis secara deskriptif yang meliputi karakteristik responden baik kooperator dan non kooperator yang terdiri dari sebaran tingkat pendidikan, sebaran umur, dan sebaran usaha atau sumber mata pencaharian responden, sebaran lama usaha beternak. Selanjutnya, untuk mengetahui perspesi dan pemahaman petani atas introduksi teknologi akan dianalisis secara deskriptif. keuntungan usahatani responden akan dianalisis dengan menggunakan formula: Penerimaan adalah total hasil dikalikan harga pada saat itu (Soekartawi, 1986) dengan formulasi sebagai berikut :

Dimana:

$$
\mathrm{TR}=\mathrm{Y} \cdot \mathrm{Py}
$$

$\mathrm{TR} \quad=$ total penerimaan $(\mathrm{Rp})$

$\mathrm{Y} \quad$ = produksi yang diperoleh dari usaha ternak kambing (Ekor)

Py $\quad=$ harga produk $Y(R p)$

Pendapatan adalah hasil pengurangan antara penerimaan dengan toal biaya (Soekartawi, 1986) dengan formulasi sebagai berikut :

Dimana:

$$
\mathrm{NR}=\mathrm{TR}-\mathrm{TEC}
$$

$\mathrm{NR}$ = pendapatan usaha ternak kambing (net revenue) $(\mathrm{Rp})$

$\mathrm{TR}=$ total penerimaan usaha ternak kambing (total revenue) (Rp)

TEC = total biaya yang secara nyata dikeluarkan (total eksplisit cost (Rp) 


\section{HASIL DAN PEMBAHASAN}

\section{Karakteristik Responden}

\section{Sebaran Responden Menurut Umur}

Berdasarkan hasil olah data primer, diketahui bahwa rata-rata umur responden peternak kooperator yang berada pada usia produktif adalah yang berkisar antara umur 28 - 55 tahun, sedangkan yang berada diatas umur produktif yakni berada diatas umur 56 tahun. Dari sebaran data umur peternak mengindikasikan bahwa sekitar $83 \% \%$ berada pada umur produktif sedangkan sekitar $17 \%$ berada pada umur kurang produktif.

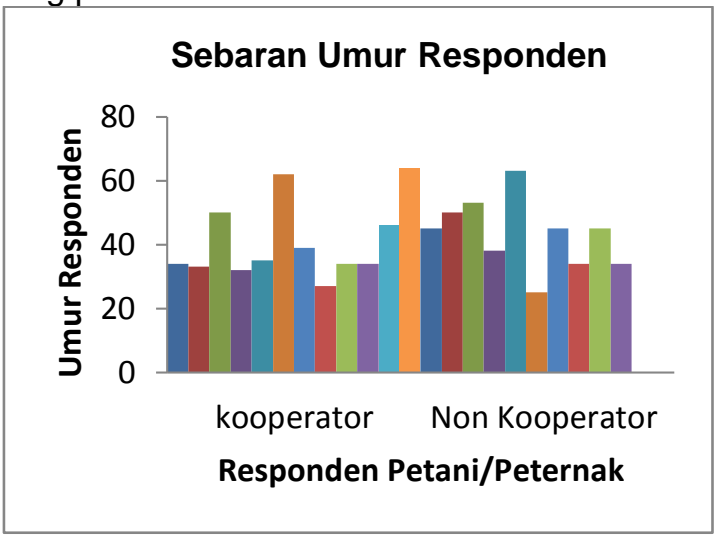

Gambar 1. Sebaran umur responden (kooperator dan non kooperator) hasil survey dan wawancara (data primer diolah)

Sebaran umur memberikan indikasi adanya tenaga kerja yang produktif (petani kooperator) dalam mengelola usahanya, sehingga memberikan peluang bagi peningkatan produktifitas ternak (Mulatmi et al., 2016). Lebih lanjut, untuk non kooperator sebaran data umur mengindikasikan $90 \%$ berada pada umur produktif, sedangkan $10 \%$ berada pada umur non produktif. Sebaran ini menunjukan bahwa petani kooperator dan non kooperator pada 2 desa kajian berada pada sebaran umur produktif (Gambar 1).

\section{Sebaran Responden Menurut Jenis Pekerjaan Utama}

Berdasarkan hasil survey sebaran responden menurut jenis pekerjaan utama menunjukan bahwa memelihara ternak kambing merupakan usaha yang paling dominan oleh petani kooperator maupun non kooperator (100\%), disusul oleh kegiatan bertani/berkebun (75\% kooperator dan $90 \%$ non kooperator), memelihara ternak sapi (42\% kooperator dan 30\% non kooperator), sedangkan jenis pekerjaan lainnya adalah buruh dan wiraswasta dalam persentase yang kecil (gambar 2).

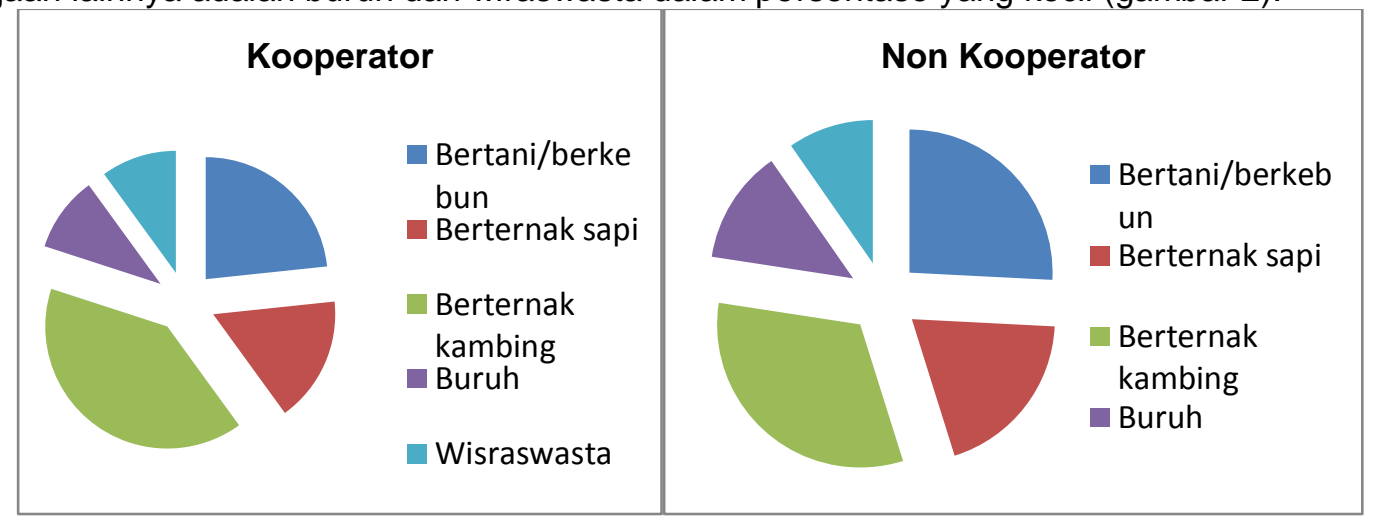

Gambar 2. Sebaran jenis pekerjaan (kooperator dan non kooperator) hasil survey dan wawancara (data primer diolah)

\section{Sebaran Responden Berdasarkan Pengalaman Berternak Kambing}

Pengalaman dalam memelihara kambing menjadi perhatian utama dalam kajian ini, hal ini menjadi faktor pertimbangan utama khususnya dalam hal kemampuan untuk mengadopsi teknologi IB kambing. Faktor pengalaman berternak kambing ini diharapkan menjadi faktor pendukung untuk meningkatkan adopsi inovasi kegiatan pengkajian ini. Dari sebaran responden yang diperoleh dari hasil survey dan wawancara menunjukan bahwa baik kooperator maupun non kooperator memiliki 
pengamalan beternak kambing minimal selama 3 tahun. Hasil olah data primer menunjukan bahwa rataan pengalaman berternak kambing petani kooperator adalah 7 tahun, sedangkan untuk non kooperator rataan adalah 6,8 tahun. Data tersebut memperlihatkan bahwa kooperator dan non kooperator memiliki pengalaman berternak kambing rata-rata 6-7 tahun. Tingkat pengalaman berusahatani merupakan factor yang berpengaruh terhadap tingkat adopsi inovasi peternak (Nugraha et al., 2016).

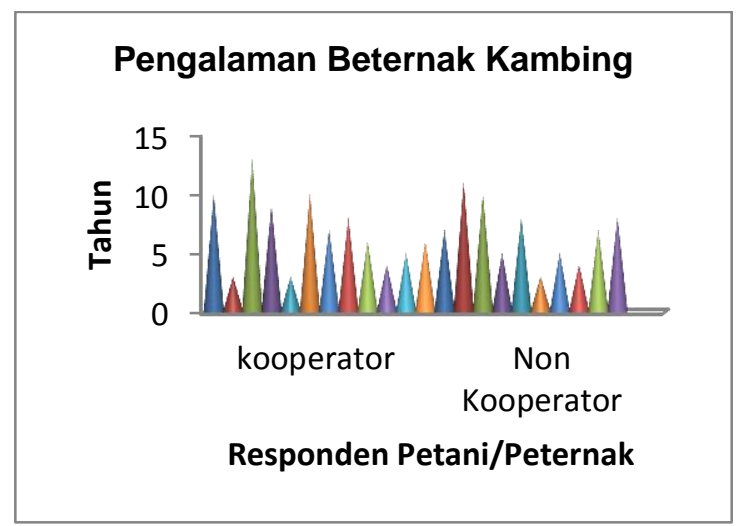

Gambar 3. Pengalaman beternak kambing petani responden (kooperator dan non kooperator) hasil survey dan wawancara (data primer diolah)

Data pada Gambar 3 di atas menunjukan bahwa berternak kambing bukan lagi merupakan pekerjaan sampingan responden di 2 desa lokasi, hal ini ,menunjuklan bahwa memelihara kambing sudah menjadi pilihan utama dalam penghasilan pendapatan dan mengindikasikan bahwa berternak kambing tidak akan berkembang jika hanya sebagai pekerjaan tambahan (Masrah et al., 2016).

\section{Sebaran Reponden Berdasarkan Tingkat Pendidikan}

Hasil olah data primer menunjukan bahwa sebaran responden memiliki tingkat pendidikan dominan adalah tamat SMP dan Tamat SMA untuk kooperator, sedangkan non kooperator sebaran responden menunjukan bahwa tamat SMA dan tidak tamat SMP menjadi sebaran yang dominan. Namun, secara umum sebaran responden menunjukan bahwa rataan pendidikan adalah 6-12 tahun baik kooperator dan non kooperator. Tingkat pendidikan ini diharapkan dapat menjadi faktor pendukung keberhasilan adopsi inovasi teknologi IB kambing di lokasi kajian. Dalam sebuah usaha semakin tinggi tingkat pendidikan seseorang, akan mem-pengaruhi dalam pengambilan keputusan atas usahanya dan memiliki daya analisis yang tinggi terhadap peluang-peluang yang ada disekitarnya untuk peningkatan usahanya (Mahalubi et al., 2019).

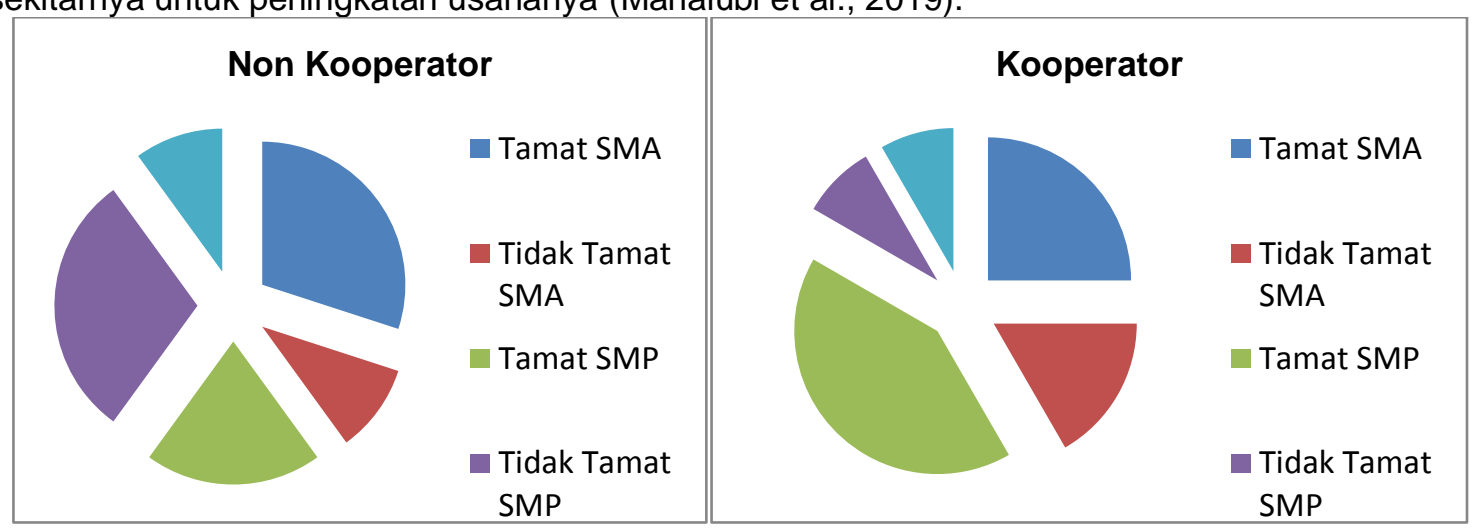

Gambar 4. Sebaran tingkat pendidikan responden (kooperator dan non kooperator) hasil survey dan wawancara (data primer diolah)

\section{Karakteristik Usahatani Kambing}

Tabel 1 berikut ini menggambarkan karakteristik pemeliharaan ternak kambing di lokasi kajian. Hasil survey memperlihatkan bahwa kambing kacang merupakan jenis kambing yang dominan dipelihara baik kooperator dan non kooperator, walaupun mereka juga memelihara jenis kambing Peranakan Etawa (Rahmah et al., 2018 ). Data juga menunjukan bahwa kooperator dan non kooperator memelihara ternak kambing di dalam kandang dengan sistem pemberian pakan cut and 
carry dengan jenis hijaua pakan dominan yang diberikan adalah daun gamal, lamtoro, dan daun nangka yang bersumber dari hijauan lokal yang cukup tersedia sepanjang tahun.

Sistem perkandangan untuk ternak kambing sudah lama diterapkan oleh para peternak di 2 lokasi kajian dengan alasan utama adalah faktor keamanan, sedangkan alasan lainnya adalah agar ternak tidak mengganggu tanaman milik petani lain, dan mudah dikontrol serta menghindari penyakit atau keracunan pada ternak. Ketersediaan hijauan pakan di 2 lokasi kajian sepanjang tahun menjadi faktor kemudahan petani dalam pemberian pakan ternak, namun dalam jangka panjang dikhawatirkan ketersediaan akan semakin berkurang khususnya di musim kemarau, oleh sebab itu perlu dilakukan tindakan antisipasi dengan menanam hijauan pakan yang berkualitas untuk pakan ternak (Mahalubi et al., 2019) menyatakan perilaku sosial dan perilaku demografi dapat dibedakan dari sistem beternak yang berdampak pada pengambilan keputusan dalam resiko usaha sebagai dinamika kelompok peternak.

Tabel 1. Karakteristik pemeliharaan ternak kambing di dua lokasi kajian

\begin{tabular}{|c|c|c|}
\hline Karakteristik usahatani kambing & Kooperator $(n=30)$ & Non Kooperator $(\mathrm{n}=30)$ \\
\hline Jenis kambing yang dipelihara & & \\
\hline - Kambing Kacang & $60 \%$ & $70 \%$ \\
\hline - Kambing PE & $40 \%$ & $30 \%$ \\
\hline Sistem pemeliharaan ternak & $\begin{array}{l}\text { Dikandangkan } \\
(100 \%)\end{array}$ & Dikandangkan (100\%) \\
\hline Sistem pemberian pakan & $\begin{array}{l}\text { Cut and Carry } \\
(100 \%)\end{array}$ & $\begin{array}{l}\text { Cut and Carry } \\
(100 \%)\end{array}$ \\
\hline Jenis pakan yang diberikan & $\begin{array}{l}\text { Daun gamal, lamtoro, } \\
\text { daun nangka }\end{array}$ & $\begin{array}{c}\text { Daun gamal, lamtoro, } \\
\text { daun nangka }\end{array}$ \\
\hline $\begin{array}{l}\text { Usaha yang dilakukan untuk penyediaan } \\
\text { pakan }\end{array}$ & - & - \\
\hline Ketersediaan pakan sepanjang tahun & $\begin{array}{c}\text { Tersedia secara alami } \\
(100 \%)\end{array}$ & $\begin{array}{c}\text { Tersedia secara alami } \\
(100 \%)\end{array}$ \\
\hline
\end{tabular}

Sumber : Data primer diolah

Selanjutnya, data pada Tabel 2 menunjukan estimasi nilai pendapatan bersih dari hasil jual ternak kambing dewasa umur 1 tahun (rataan) hasil IB adalah sebesar Rp. 3.000 .000 per tahun per ekor untuk petani kooperator, sedangkan untuk non kooperator (Non IB) sebesar Rp. 1.300.000. Tinggi nya nilai jual kambing hasil IB menunjukan performasi yang baik hal ini disebabkan ternak hasil IB memiliki postur tubuh yang lebih baik bila dibandingkan dengan kambing kacang, dan bobot tubuh yang lebih besar (Zulfanita, 2011).. Biaya produksi meliputi upah pemberian pakan dan pembelian vitamin sebesar Rp. 500.000 per tahun.

Tabel 2. Estimasi analisis ekonomi usahatani ternak kambing ( 1 ekor kambing) periode pemeliharaan 1 tahun (hasil IB)

\begin{tabular}{ccccccc}
\hline & \multicolumn{2}{c}{ Kooperator $(\mathrm{n}=30)($ hasil IB $)$} & \multicolumn{3}{c}{ Non Kooperator $(\mathrm{n}=30)$} \\
\cline { 2 - 7 } No. & $\begin{array}{c}\text { Nilai Jual } \\
(\text { Penerimaan }) \\
(\mathrm{Rp})\end{array}$ & $\begin{array}{c}\text { Biaya } \\
\text { Produksi } \\
(\mathrm{Rp})\end{array}$ & $\begin{array}{c}\text { Pendapatan } \\
(\mathrm{Rp})\end{array}$ & $\begin{array}{c}\text { Nilai Jual } \\
(\text { Penerimaan }) \\
(\mathrm{Rp})\end{array}$ & $\begin{array}{c}\text { Biaya } \\
\text { Produksi } \\
(\mathrm{Rp})\end{array}$ & $\begin{array}{c}\text { Pendapatan } \\
(\mathrm{Rp})\end{array}$ \\
\hline 1. & 3.000 .000 & 500.000 & 2.500 .000 & 1.800 .000 & 500.000 & 1.300 .000 \\
\hline
\end{tabular}

Sumber : Data primer diolah

\section{Sikap dan Persepsi Peternak Terhadap Kawin Suntik Atau Inseminasi Buatan (IB) Ternak Kambing}

Diseminasi teknologi Iseminasi Buatan (IB) masih mengalami persoalan di tingkat petani atau peternak ditinjau dari pelayanan IB terutama pada wilayah terpencil, ketersediaan petugas inseminator, dan pengetahuan peternak mengenai teknologi IB (Ediset \& Heryanto, 2018). Adopsi inovasi teknologi pada dasarnya dipengaruhi oleh persepsi dan karakteristik peternak. Ke dua hal tersebut merupakan faktor penting dalam hal adopsi teknologi (Sasmito, 2017). Kondisi tersebut tercermin di 2 lokasi kajian walaupun homogenitas masyarakat tampak menonjol, namun secara individu mereka memiliki perilaku yang berbeda. Tabel 3 dibawah merupakan pengukuran persepsi peternak terhadap teknologi IB sebagai variable utama dengan sub variable meliputi: (1) Pengetahuan peternak terhadap teknologi IB; (2) keinginan atau minat petani dalam menerapkan 
teknologi IB; (3) Penilaian peternak terhadap hasil teknologi IB; dan (4) Persepsi petani terhadap keseluruhan hasil penerapan teknologi IB.

Tabel 3. Persepsi peternak terhadap Inseminasi Buatan (IB) kooperator

\begin{tabular}{|c|c|c|c|c|}
\hline \multirow{3}{*}{ No. } & \multirow{3}{*}{ Uraian } & \multicolumn{3}{|c|}{ Kategori $(n=30)$} \\
\hline & & Baik & Cukup & Kurang \\
\hline & & \multicolumn{3}{|c|}{--------------------\%---------------------- } \\
\hline 1. & Pengetahuan terhadap IB & 32,50 & 45,00 & 22,50 \\
\hline 2. & Minat terhadap IB & 52,50 & 17,50 & 30,0 \\
\hline 3. & Penilaian terhadap IB & 59,87 & 11,87 & 28,26 \\
\hline 4. & Persepsi terhadap IB & 48,29 & 24,79 & 26,92 \\
\hline
\end{tabular}

Sumber : Data primer diolah

Hasil pelaksanaan program IB pada ternak kambing di 2 lokasi kajian terlihat pada table $3 \mathrm{di}$ atas yang menunjukan bahwa pengetahuan peternak terhadap teknologi IB masuk pada kategori cukup (45\%) dan baik sebesar $32,50 \%$. Selanjutnya pada sub variable minat peternak terhadap IB menunjukan bahwa peternak memiliki keinginan atau minat untuk menerapkan teknologi IB yaitu pada kategori baik sebesar $52,50 \%$. Hal yang sama juga terlihat pada pengukuran sub variable penilaian peternak atau kooperator terhadap teknologi IB yaitu pada kategoro baik sebesar $59,87 \%$. Lebih lanjut, pengukuran persepsi peternak pada kategori baik sebesar 48,29\% mengindikasikan keberhasilan pelaksanaan program IB ternak kambing di 2 lokasi kajian.

\section{Adopsi Inovasi IB Kambing \\ Penilaian Peternak terhadap Ciri-Ciri Inivasi Inseminasi Buatan (IB)}

Proses adopsi inovasi teknologi membutuhkan tahapan untuk pembuatan keputusan yang terdiri dari kesadaran, minat, penilaian, mencoba dan menerima (Mahalubi et al., 2019). Inovasi teknologi IB menurut (Awais \& Khan, 2014) sebagai stimulus bagi para peternak, hal ini disebabkan adanya sifat keuntungan relative, kesesuaian dengan keadaan (kompatabilitas), kompleksitas atau tingkat kesukaran, triabilitas atau dapat diujicobakan pada skala kecil dan sifat observabilitas atau dapat dilihat hasil dari uji coba tersebut.

Tabel 4. Penilaian peternak terhadap ciri-ciri inovasi Inseminasi Buatan (IB) kambing

\begin{tabular}{clccc}
\hline & \multicolumn{1}{c}{ Uraian } & \multicolumn{3}{c}{ Kategori (N=30) } \\
\cline { 3 - 5 } No. & & Baik & Cukup & Kurang \\
\cline { 3 - 5 } & & 51,87 & 8,13 & 40,00 \\
\hline 1. & Keuntungan relatif & 62,50 & 10,00 & 27,50 \\
2. & Kompatabilitas & 30,00 & 28,75 & 41,25 \\
3. & Kemudahan penerapan IB & 77,50 & 10,00 & 12,50 \\
4. & Triabilitas & 77,50 & 2,50 & 20,00 \\
5. & Observabilitas & 59,87 & 11,87 & 28,26 \\
6. & Penilaian peternak & &
\end{tabular}

Sumber : Data primer diolah

Hasil analisis data dapat dilihat pada Table 4 di atas yang menunjukan bahwa inovasi teknologi IB memiliki keuntungan relative dengan kategori baik sebesar $51,87 \%$ yang mengindikasikan bahwa keputusan petani dalam menerima teknologi IB berdasarkan keuntungan dari penjualan yang diperoleh dari hasil ternak IB (Maesya \& Rusdiana, 2018); (Awais \& Khan, 2014). Selanjutnya, dari sisi kompatabilitas, sebagian besar peternak kooperator $(62,50 \%)$ menilai bahwa penerapan teknologi IB sesuai dengan kebutuhan para peternak, namun $27,50 \%$ merasa khawatir akan resiko kematian induk betina yang disebabkan perubahan penampilan fisik yang lebih besar dari anak kambing hasil IB (Quddus, 2012).

Lebih lanjut dilihat dari pengukuran variable kompleksitas $41,25 \%$ peternak kooperator berpendapat bahwa penerapan teknologi IB memiliki tingkat kerumitan yang cukup tinggi. Hasil interview menunjukan bahwa kondisi tersebut disebabkan oleh tingkat keterampilan yang tinggi sangat diperlukan sebagai inseminator. Oleh sebab itu, pelatihan keterampilan peternak sebagai inseminator sangat diperlukan sebagai upaya keberhasilan program IB ternak kambing (Muhyidin, Arman, \& Zaenuri, 2019). Salah satu aspek yang cukup penting dalam penerimaan inovasi yaitu dari sisi triabilitas yang menunjukan bahwa $77,50 \%$ peternak kooperator menilai bahwa teknologi tersebut 
dapat diujicobakan dalam skala yang kecil, hal ini berarti tingkat resiko kegagalan dapat diperkecil (Pateda, 2010); (Utomo \& Rasminati, 2012).

\section{KESIMPULAN}

Karakteristik peternak di 2 lokasi kajian menunjukan bahwa sistem usahatani ternak kambing yang berkembang adalah model semi-intensif, dengan ciri-ciri ternak kambing dikandangkan setiap hari, hijauan pakan adalah hijauan lokal dengan model pemberian pakan cut and carry. Secara keseluruhan pengukuran persepsi petani terhadap IB menunjukan bahwa perspesi petani terhadap kegiatan IB di lokasi kajian menunjukan kategori baik (48,29\%), cukup baik $(24,79 \%)$ dan sisasnya 26,92\% kategori kurang baik. Penilaian peternak terhadap inovasi teknologi IB secara keseluruhan dari penilaian petani terhadap inovasi tersebut, yaitu dari sisi keuntungan relatif, kompatabilitas, kemudahan penerapan IB, triabilitas, dan obervabilitas menunjukan persentase baik $(59,87 \%$, cukup baik $(11,87 \%)$ dan kurang baik (28,26\%). Teknologi IB di 2 lokasi kajian secara merata (100\%) sudah diterapkan pada petani kooperator, selain itu perbaikan kandang kambing sudah diterapkan oleh peternak secara keseluruhan. Adopsi inovasi teknologi IB menunjukan bahwa teknologi tersebut telah tersebar luas bukan hanya diterapkan oleh petani non kooperator (3 orang) namun juga petani di luar non kooperator (1 orang) dan petani di luar desa kajian (1 orang).

\section{REFERENCES}

Nugraha, A., Abdullah, A., \& Sirajuddin, N. (2016). Tingkat Adopsi Inovasi Ib (Inseminasi Buatan) Pada Peternak Sapi Potong Di Kecamatan Lalabata Kabupaten Soppeng Jurnal Aves, 10(2), 8.

Maesya, A., Rusdiana, S. (2018). Prospek Pengembangan Usaha Ternak Kambing dan Memacu Peningkatan Ekonomi Peternak. Agriekonomika, 7(2), 13.

Ediset, \& Heryanto, E. (2018). Tingkat Keberhasilan dan Pengaruh Status Sosial Ekonomi Terhadap Adopsi Inovasi Inseminasi Buatan (IB) Pada Usaha Peternakan Kerbau di Kabupaten Padang Pariaman Sumatera Barat. Jurnal Peternakan Sriwijaya, 7(1), 8.

Susanto, E., \& Dahlan, M. (2017). Studi Penerapan Estrus Synchronization Dan Teknologi Ib Jenis Boer Terhadap Respon Birahi Dan Kebuntingan Kambing Lokal Pada Kelompok Petani Peternak "Telaga Ternak Mandiri" Di Kabupaten Lamongan. Jurnal Ternak, 8(2), 7.

Kurniasih, N., Fuah,M., \& Priyanto, R. (2013). Karakteristik Reproduksi Dan Perkembanga Populasi Kambing Peranakan Etawah Di Lahan Pasca Galian Pasir. Jurnal IImu Produksi dan Teknologi Peternakan 1(3), 5.

Hasri, P.L., Suharyati, S., \& Sulastri. (2018). Estimasi Output Berbagai Bangsa Kambing Di Desa Dadapan Kecamatan Sumberejo Kabupaten Tanggamus Jurnal Riset dan Inovasi Peternakan 2(1), 5 .

Masrah, Hafid, H., \& Saili, T. (2016). Kajian Produktivitas Ternak Kambing Pada Sistem Pemeliharaan Yang Berbeda Di Kecamatan Andoolo Barat Kabupaten Konawe Selatan. Jurnal Ilmu danTeknologi Peternakan Tropis, 3(1), 11.

Riyadhi, M., Rizal, M., Wahdi, A. (2017). Diseminasi Teknologi Inseminasi Buatan Menggunakan Semen Kambing Peranakan Etawa (PE) dengan Pengencer Air Kelapa Muda dan Kuning Telur di Kecamatan Bati Bati Kabupaten Tanah Laut Kalimantan Selatan Panrita Abdi, 1(2), 5.

Muhyidin, Arman, C., Zaenuri, L.A. (2019). Analisis Tingkat Pengetahuan, Sikap, dan Motivasi Peternak Sapi dalam Adopsi Teknologi Inseminasi Buatan di Sumbawa Barat Jurnal IImu danTeknologi Peternakan Tropis, 6(3), 8.

Pateda, S.Y. (2010). Tingkat Adopsi Petani Terhadap Teknologi Inseminasi Buatan Pada Sapi Di Kecamatan Paguyama. Jurnal Sainstek, 5(1), 7.

Quddus, M. (2012). Adoption of dairy farming technologies by small farm holders: practices and constraints Bangladesh Journal of Animal Science, 41(2), 11.

Mahalubi, R.I., Rintjap, A.K., Malingkas, J.A., \& Oley, F.S. (2019). Respon Peternak Sapi Potong Terhadap Penerapan Teknologi Inseminasi Buatan (lb) Di Desa Tondegesan Dua Kecamatan Kawangkoan Kabupaten Minahasa. Zootec, 39(1), 10.

Sasmito, P. (2017). Adopsi Inovasi Budidaya Kambing Peranakan Etawa (Pe) Di Kabupaten Kulon Progo Provinsi D.I. Yogyakarta. Komuniti, 8(2), 11.

Mulatmi, S.N.W., Guntoro, B., Widyobroto, B.P., Nurtini, S., \& Pertiwiningrum, A. (2016). Strategi Peningkatan Adopsi Inovasi Pada Peternakan Sapi Perah Rakyat Di Daerah Istimewa Yogyakarta, Jawa Tengah, Dan Jawa Timur Bulletin Peternakan, 40(3), 8. 
Utomo, S., \& Rasminati, N. (2012). Penerapan Teknologi Inseminasi Buatan Pada Ternak Domba Inotek, 16(1), 9.

Soekartawi. (1986). IImu Usahatani dan Penelitian Untuk Pengembangan Petani Kecil: Universitas Indonesia.

Rahmah, U.I.L., Imanudin, O., \& Permadi, D. (2018). Analisis Faktor-Faktor Yang Berhubungan Dengan Tingkat Keberhasilan Inseminasi Buatan Pada Kambing Kacang (Capra hircus) Jurnal IImu Pertanian dan Peternakan, 6(2), 9.

Zulfanita. (2011). Kajian Analisis Usaha Ternak Kambing Di Desa Lubangsampang Kecamatan Pituruh Kabupaten Purworejo Mediagro, 7(2), 7. 